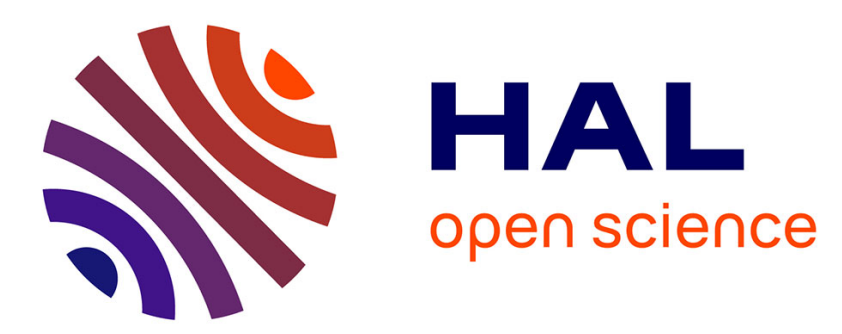

\title{
Scintillation of Sol-Gel derived Lutetium orthophosphate doped with rare earth ions.
}

Christelle Mansuy, Jean-Marie Nedelec, Christophe Dujardin, Rachid Mahiou

\section{To cite this version:}

Christelle Mansuy, Jean-Marie Nedelec, Christophe Dujardin, Rachid Mahiou. Scintillation of SolGel derived Lutetium orthophosphate doped with rare earth ions.. Journal of Sol-Gel Science and Technology, 2006, 38, pp.97-105. 10.1007/s10971-005-5639-9 . hal-00154713

\section{HAL Id: hal-00154713 https://hal.science/hal-00154713}

Submitted on 14 Jun 2007

HAL is a multi-disciplinary open access archive for the deposit and dissemination of scientific research documents, whether they are published or not. The documents may come from teaching and research institutions in France or abroad, or from public or private research centers.
L'archive ouverte pluridisciplinaire HAL, est destinée au dépôt et à la diffusion de documents scientifiques de niveau recherche, publiés ou non, émanant des établissements d'enseignement et de recherche français ou étrangers, des laboratoires publics ou privés. 


\title{
Scintillation of Sol-Gel derived Lutetium orthophosphate doped with rare earth ions.
}

\author{
C. Mansuy ${ }^{1}$, J.M. Nedelec ${ }^{1 *}$, C. Dujardin ${ }^{2}$ and R. Mahiou ${ }^{1}$ \\ ${ }^{1}$ Laboratoire des Matériaux Inorganiques, CNRS UMR 6002, Université Blaise Pascal et Ecole \\ Nationale Supérieure de Chimie de Clermont-Ferrand, \\ 63177 Aubière cedex, France \\ ${ }^{2}$ Laboratoire de Physico-Chimie des Matériaux Luminescents, CNRS UMR 5620 Université \\ Claude Bernard, 10 rue A.M. Ampère 69622 Villeurbanne Cedex, France.
}

${ }^{*}$ Corresponding author : Dr J.M. Nedelec

Laboratoire des Matériaux Inorganiques UMR 6002

Université Blaise Pascal, 24 Avenue des Landais

63177 Aubière Cedex, FRANCE

E-mail : j-marie.nedelec@univ-bpclermont.fr 


\begin{abstract}
In this paper, the synthesis, the characterization and the scintillation properties of $\mathrm{LuPO}_{4}$ doped, with several concentrations of $\mathrm{Ce}^{3+}, \mathrm{Eu}^{3+}$ and $\mathrm{Tb}^{3+}$ ions, are presented. These materials have been synthesized by sol-gel process. The purity of powders has been verified by X-Ray diffraction and the results confirm the xenotime structure of all the materials. A thermogravimetric analysis allows the obtention of informations on the crystallisation of $\mathrm{LuPO}_{4}$ and the study of its evolution from the amorphous to crystalline form. The morphology of the powders has been studied by Scanning Electron Microscopy and shows that the powders are constituted of small particles with narrow size distribution. Optical properties have been studied in order to determine the scintillation performances of these materials. The optima are obtained for $\mathrm{Ce}^{3+}, \mathrm{Eu}^{3+}$ and $\mathrm{Tb}^{3+}$ concentration of respectively $0.1 \%, 10 \%$ and $5 \%$ with high scintillation yields. This study thus confirms the potentialities of these materials as scintillators.
\end{abstract}




\section{Introduction}

Nowadays, research focussed on inorganic scintillators is in constant development. These materials, that convert high energy radiation into UV-Visible light, are used in various applications [1]: medical imaging, high energy physics, airport security and industrial control. For medical imaging applications, the conversion yield of the scintillating materials has to be improved in order to minimize the patient X-rays exposure. The development of materials that present high density are particularly interesting in order to get efficient X-ray absorption.

The sol-gel process seems to be a good solution for the elaboration of scintillating materials. Indeed, the use of molecular precursors in solution confers an important chemical homogeneity to these materials. Moreover, the sol-gel route allows the elaboration of materials of different composition and doped easily with different ions, in various concentration. The sol-gel derived materials are synthesized at lower temperature than the ones elaborated by classical solid state synthesis. This point is economically important and can sometimes lead to new phases.

Because of the required high density, lutetium based oxides materials are very interesting candidates. In order to exhibit luminescence properties, these materials are generally doped with rare earth ions. $\mathrm{LuPO}_{4}$, which is known as an efficient scintillator [2], is the subject of this work and has been doped with $\mathrm{Ce}^{3+}, \mathrm{Eu}^{3+}$ and $\mathrm{Tb}^{3+}$ ions.

The emission of $\mathrm{Ce}^{3+}$ doped scintillator is based upon intense and fast $5 \mathrm{~d} \rightarrow 4 \mathrm{f}$ transitions and occurs in the UV-blue range for which effective detectors are available.

The materials doped with $\mathrm{Eu}^{3+}$ or $\mathrm{Tb}^{3+}$ ions emit in the visible range but with long decay time.

\section{Experimental Section}

\section{Materials preparation}

\section{Sol-Gel derived samples}

In a first step, a mixture of Lutetium and $\mathrm{Ln}$ alkoxides $(\mathrm{Ln}=\mathrm{Eu}, \mathrm{Tb}$ or $\mathrm{Ce})$ is prepared by metathesis reaction of lutetium anhydrous chloride with potassium isopropanolate as reported for various metallic alkoxides [3]. All manipulations are carried out under dry argon atmosphere to prevent any influence of air moisture. High purity chlorides (Aldrich) were used; they were dried under vacuum before use to ensure total absence of water. $\mathrm{LuCl}_{3}$ and $\mathrm{LnCl}_{3}$ were mixed together in anhydrous 2-propanol in required amounts during 2 hours. Potassium isopropoxide was prepared by reacting metallic potassium (Aldrich) with anhydrous 2-propanol (Accros). Anhydrous 2-propanol 
was dried and stored over molecular sieve. Lu/Ln chlorides mixture is then reacted with the potassium alcoholate with a $\mathrm{K} /(\mathrm{Lu}+\mathrm{Ln})$ ratio in slight excess with respect to the stoechiometric $\mathrm{K} /(\mathrm{Lu}+\mathrm{Ln})=3$ molar ratio. The mixture was then refluxed for 3 hours $\mathrm{t} 85^{\circ} \mathrm{C}$, white precipitate of $\mathrm{KCl}$ appeared rapidly attesting the formation of the $\mathrm{Lu} / \mathrm{Ln}$ alkoxides. The obtained sol labeled sol 1 is then cooled down to room temperature.

The phosphorus precursor ( $\mathrm{sol} 2$ ) is prepared by reacting anhydrous $\mathrm{P}_{2} \mathrm{O}_{5}$ with isopropanol yielding a mixture of hydroxo alkoxides $\left(\mathrm{O}=\mathrm{P}(\mathrm{OH})_{\mathrm{x}}(\mathrm{OiPr})_{3-\mathrm{x}}, \mathrm{x}=0,1,2,3\right)$.

Sol 1 and sol 2 are then mixed under stirring and immediate precipitation occurs. The mixture was then magnetically stirred for 15 hours at room temperature. The solid is then isolated by centrifugation and elimination of the supernatant and washed thoroughly with deionized water in order to eliminate water soluble $\mathrm{KCl}$. The badly defined amorphous lutetium alkoxo phosphate is dried for about 6 hours at $80^{\circ} \mathrm{C}$ and the dry xerogel obtained is then fired at $1100{ }^{\circ} \mathrm{C}$ for 24 hours. $\mathrm{LuPO}_{4}$ powders doped with $\mathrm{Ce}^{3+}, \mathrm{Tb}^{3+}$ and $\mathrm{Eu}^{3+}$ ions have been prepared with an atomic ratio of $0.1,0.2,0.3,0.5$ and $1 \%$ for $\mathrm{Ce}^{3+}, 0.2,0.5,1$, and $5 \%$ for $\mathrm{Tb}^{3+}$ and $0.2,0.5,1,5$ and $10 \%$ for $\mathrm{Eu}^{3+}$.

\section{Co-precipitated samples}

For sake of comparison, $\mathrm{Eu}^{3+}$ doped $\mathrm{LuPO}_{4}$ samples have been prepared by co-precipitation. A mixture of $\mathrm{Lu}_{2} \mathrm{O}_{3}$ and $\mathrm{Eu}_{2} \mathrm{O}_{3}$ is prepared in required amount. A solution of phosphoric acid $(\mathrm{C}=0.2 \mathrm{M})$ is then added to the oxides mixture and refluxed for 15 hours. The resulting white powder is then washed thoroughly with de-ionized water and finally fired in the same conditions than sol-gel derived samples $\left(1100^{\circ} \mathrm{C}\right.$ for 24 hours $)$.

\section{Characterization}

X-Ray diffraction patterns have been measured for all powders on a Siemens D501 diffractometer working in the Bragg-Brentano configuration with $\mathrm{Cu}-\mathrm{K}_{\alpha}$ radiation $(\lambda=1.5406 \AA \hat{)})$.

Infrared spectra were recorded on a Perkin Elmer 2000 FTIR spectrometer using the $\mathrm{KBr}$ pellet technique.

Thermogravimetric analysis were performed using a Metler Toledo 851 apparatus. Samples were heated in air with a rate of $1^{\circ} \mathrm{C} \cdot \mathrm{min}^{-1}$.

Micrographs were recorded using a Cambridge StereoScan 360 SEM operating at $20 \mathrm{kV}$. Samples were prepared by depositing a small quantity of powder on adhesive carbon film before coating the surface with gold. 
The excitation spectra of all the powders, doped with $\mathrm{Ce}^{3+}, \mathrm{Eu}^{3+}$ or $\mathrm{Tb}^{3+}$, were recorded at room temperature using a Xenon lamp as continuous excitation source and a Triax 320 monochromator coupled with a CCD detector.

The scintillation spectra were recorded with a Jobin-Yvon Triax 320 monochromator coupled with a CCD camera after excitation of the samples with a tungsten X-ray tube working at $35 \mathrm{kV}$ and $15 \mathrm{~mA}$. The signal was collected near the sample with an optical fiber. For relative conversion yield estimation, the samples were placed in a quartz tube with a fixed position throughout the measurements. For measurements of scintillation yields, of $\mathrm{Ce}^{3+}$ or $\left(\mathrm{Eu}^{3+}, \mathrm{Tb}^{3+}\right)$ doped samples, polycristalline $\mathrm{BGO}$ or $\mathrm{Gd}_{2} \mathrm{O}_{2} \mathrm{~S}: \mathrm{Tb}^{3+}$ powder were respectively used as a standard.

Emission spectra were recorded at room temperature with a single monochromator Jobin Yvon HR 100 spectrometer. For $\mathrm{Eu}^{3+}$, resonant excitation in the ${ }^{5} \mathrm{D}_{0}$ level was achieved using a ND62-Continuum dye laser pumped by a frequency doubled pulsed Continuum Surelite I $\mathrm{Nd}^{3+}$ :YAG laser. A mix of Rhodamine 590 and 610 was used for the dye solution. For $\mathrm{Tb}^{3+}$, a pulsed nitrogen laser (Jobin Yvon) was used with excitation wavelength $\lambda=337.1 \mathrm{~nm}$.

Time resolved emission was monitored with an EG\&G Boxcar and fluorescence lifetimes were measured with a LeCroy $400 \mathrm{MHz}$ oscilloscope.

The afterglow measurements were performed at room temperature on the samples corresponding to concentration optima. The excitation was performed during $10 \mathrm{~s}$ with a X-ray source working at 40 $\mathrm{kV}$ and $35 \mathrm{~mA} . \mathrm{Gd}_{2} \mathrm{O}_{2} \mathrm{~S}: \mathrm{Tb}^{3+}$ powder was used as a reference.

\section{Results and Discussion}

\section{Characterization}

\section{$X$-Ray Diffraction}

Figure 1 shows the XRD patterns for $\mathrm{LuPO}_{4}$ powders doped with $\mathrm{Ce}^{3+}, \mathrm{Eu}^{3+}$ and $\mathrm{Tb}^{3+}$ ions. Orthophosphates $\mathrm{LnPO}_{4}$ present two crystalline types depending on the nature of $\mathrm{Ln}^{3+}$ cation. In effect, $\mathrm{LuPO}_{4}$ crystallizes with the xenotime type [4] whereas $\mathrm{CePO}_{4}$ and $\mathrm{EuPO}_{4}$ crystallize with the monazite type [5]. However the XRD patterns only show the xenotime structure of $\mathrm{LuPO}_{4}$, confirming the substitution of $\mathrm{Lu}^{3+}$ by $\mathrm{Ln}^{3+}(\mathrm{Ln}: \mathrm{Ce}, \mathrm{Eu}$ or $\mathrm{Tb}$ ) in solid solution. It is significant to specify that $\mathrm{LuPO}_{4}: \mathrm{Ce}^{3+}$ can be obtained without presence of $\mathrm{CePO}_{4}$ until a maximal $\mathrm{Ce}$ concentration of $1 \%$ at. Indeed, the X-ray diffraction pattern of a $\mathrm{LuPO}_{4}: \mathrm{Ce}^{3+}(2 \%)$ powder shows the presence of both $\mathrm{LuPO}_{4}$ and $\mathrm{CePO}_{4}$ phases. So the solid solution for $\mathrm{LuPO}_{4}$ xenotime is 
observed up to $1 \%, 10 \%$ and $5 \%$ for respectively cerium, europium and terbium ions. Solid solution limits have not been determined for $\mathrm{Eu}^{3+}$ and $\mathrm{Tb}^{3+}$ doped materials and higher concentration might be possible while keeping the xenotime structure and a monophasic material.

\section{FTIR Spectroscopy}

Fourier Transform Infra-Red spectroscopy has been carried out on different samples doped with $\mathrm{Ce}^{3+}, \mathrm{Eu}^{3+}$ and $\mathrm{Tb}^{3+}$ ions. All recorded IR spectra are similar, no significant change is observed upon doping with $\mathrm{Ce}^{3+}, \mathrm{Eu}^{3+}$ or $\mathrm{Tb}^{3+}$ ions. One of the recorded spectra is displayed in Figure 2. All the bands, observed in the range $500-1200 \mathrm{~cm}^{-1}$ correspond to $\left(\mathrm{PO}_{4}\right)^{3-}$ groups present in the structure. The bands observed between 500 and $640 \mathrm{~cm}^{-1}$ and at about $1000 \mathrm{~cm}^{-1}$ correspond respectively to bending vibrations $\delta_{\mathrm{O}-\mathrm{P}-\mathrm{O}}$ and stretching vibrations $v_{\mathrm{P}-\mathrm{O}}[6]$. At about $519 \mathrm{~cm}^{-1}$ the bands relative to stretching vibrations $v_{\text {Lu-O }}$ can also be observed. The mode observed around 3500 $\mathrm{cm}^{-1}$ corresponds to stretching mode of residual $\mathrm{OH}$ groups $\mathrm{v}_{\mathrm{O}-\mathrm{H}}$. FTIR spectra correspond to a unique phase identified as $\mathrm{LuPO}_{4}$ regardless of the doping level and the nature of the doping ion. Residual hydroxyls groups coming from the hydrolysis of alkoxides precursors are observed and will be confirmed by luminescence decay measurements.

\section{Thermal analysis}

In order to get informations on the cristallisation of $\mathrm{LuPO}_{4}$, a thermal analysis has been performed. The evolution from the amorphous to crystalline form is then studied. A thermogravimetric analysis has been carried out on $\mathrm{LuPO}_{4}$ powder elaborated by sol-gel process and the resulting thermogramm is presented in Figure 3. The first derivative is also shown in order to clearly identify the temperatures associated with the different weight losses.

A first weight loss is observed around $100^{\circ} \mathrm{C}$ and can be allotted to the elimination of adsorbed species such as alcohol or water molecules [7]. A second significant weight loss, observed at about $200^{\circ} \mathrm{C}$, corresponds to the condensation of the material. There is a condensation of the alkoxy and hydroxy groups with subsequent alcohol or water elimination. Some residual organic compounds can also be directly pyrolyzed. At this temperature, the inorganic skeleton is formed. Total loss of weight is approximately $20 \%$. 


\section{Scanning Electron Microscopy}

Scanning Electron Microscopy allows the extraction of informations about the morphology of the powders synthesized by sol-gel process and treated at $1100^{\circ} \mathrm{C}$ for 24 hours. The images, recorded at $10000 \mathrm{x}$ magnification, are given in Figure 4. The powders are homogeneous and constituted of small spherical particles. The size distribution of these particles is uniform which is a usual consequence of the use of sol-gel process.

\section{Optical properties}

\section{Excitation spectra}

Figure 5 shows the excitation spectra recorded for $\mathrm{Ce}^{3+}, \mathrm{Eu}^{3+}$ and $\mathrm{Tb}^{3+}$ doped $\mathrm{LuPO}_{4}$ powders. The measurements were performed at room temperature by fixing the emission wavelength at $360 \mathrm{~nm}, 592 \mathrm{~nm}$ and $541 \mathrm{~nm}$ for respectively $\mathrm{LuPO}_{4}: \mathrm{Ce}^{3+}(0.5 \%), \mathrm{LuPO}_{4}: \mathrm{Eu}^{3+}(10 \%)$ and $\mathrm{LuPO}_{4}: \mathrm{Tb}^{3+}(5 \%)$. Excitation spectra recorded for other concentrations are identical and are not presented.

In the case of $\mathrm{LuPO}_{4}: \mathrm{Ce}^{3+}$, two main bands are observed which correspond to the transitions between the $4 \mathrm{f}$ level and the excited $5 \mathrm{~d}$ levels: $\mathrm{T}_{2}$ and $\mathrm{E}$ of $\mathrm{Ce}^{3+}[8]$, further splitting of the $5 \mathrm{~d}$ levels is not observed probably due to the poor resolution in our room temperature spectra.

The excitation spectrum recorded for $\mathrm{LuPO}_{4}: \mathrm{Eu}^{3+}$ is constituted of lines corresponding to 4f-4f transitions. The band observed at about $470 \mathrm{~nm}$ is attributed to ${ }^{7} \mathrm{~F}_{0} \rightarrow{ }^{5} \mathrm{D}_{2}$ transition and the ones situated in the range between 300-430 nm correspond to ${ }^{7} \mathrm{~F}_{0} \rightarrow{ }^{5} \mathrm{~F}_{2},{ }^{5} \mathrm{H}_{\mathrm{J}},{ }^{5} \mathrm{D}_{4},{ }^{5} \mathrm{G}_{\mathrm{J}},{ }^{5} \mathrm{~L}_{8},{ }^{5} \mathrm{~L}_{6},{ }^{5} \mathrm{D}_{3}$ transitions. The excitation band located below $250 \mathrm{~nm}$ corresponds to the charge transfer absorption [9].

The excitation bands observed for $\mathrm{LuPO}_{4}: \mathrm{Tb}^{3+}$ powder, in the range of $300-400 \mathrm{~nm}$, are characteristic of $4 \mathrm{f}-4 \mathrm{f}$ transitions. They correspond to ${ }^{7} \mathrm{~F}_{6} \rightarrow{ }^{5} \mathrm{H}_{6},{ }^{5} \mathrm{H}_{7},{ }^{5} \mathrm{~L}_{8},{ }^{5} \mathrm{~L}_{9},{ }^{5} \mathrm{D}_{2},{ }^{5} \mathrm{G}_{5},{ }^{5} \mathrm{~L}_{10},{ }^{5} \mathrm{G}_{6}$ and ${ }^{5} \mathrm{D}_{3}$ transitions [10].

\section{Emission spectra}

The emission spectra have been recorded at room temperature under X-ray excitation for $\mathrm{LuPO}_{4}$ powders doped with different concentrations of $\mathrm{Ce}^{3+}, \mathrm{Eu}^{3+}, \mathrm{Tb}^{3+}$ ions (Figure 6).

BGO $\left(\mathrm{Bi}_{4} \mathrm{Ge}_{3} \mathrm{O}_{12}\right)$ and Gadox $\left(\mathrm{Gd}_{2} \mathrm{O}_{2} \mathrm{~S}: \mathrm{Tb}\right)$ emission spectra have also been recorded in order to estimate the scintillation yields. BGO and Gadox will respectively allow the scintillation yields measurements of $\mathrm{Ce}$ doped materials and $\mathrm{Eu}$ and $\mathrm{Tb}$ doped materials. 
In the case of $\mathrm{LuPO}_{4}: \mathrm{Ce}^{3+}$ (Figure 6 (a)), two emission bands characteristic of $5 \mathrm{~d} \rightarrow{ }^{2} \mathrm{~F}_{5 / 2}$ and $5 \mathrm{~d} \rightarrow{ }^{2} \mathrm{~F}_{7 / 2}$ transitions of $\mathrm{Ce}^{3+}$ can be observed in the region of $300-400 \mathrm{~nm}$. The optimum is obtained for $\mathrm{LuPO}_{4}: \mathrm{Ce}^{3+}(0.1 \%)$. The $\mathrm{Ce}^{3+}$ doped materials present an emission in the UV-blue range.

For $\mathrm{LuPO}_{4}: \mathrm{Eu}^{3+}$, the emission spectra have been recorded for powders elaborated by sol-gel process (Figure $6(\mathrm{~b})$ ) and by co-precipitation. The two spectra are similar and constituted of bands corresponding to ${ }^{5} \mathrm{D}_{0} \rightarrow{ }^{7} \mathrm{~F}_{\mathrm{J}}(\mathrm{J}=0-4)$ transitions of $\mathrm{Eu}^{3+}$ ions. The numbering of the different lines fairly respect the $\mathrm{D}_{2 \mathrm{~d}}$ point group. The spectral distribution of the $\mathrm{Eu}^{3+}$ doped materials results in a global orange-red emission.

$\mathrm{LuPO}_{4}: \mathrm{Tb}^{3+}$ emission spectrum (Figure 6 (c)) exhibits, in the range between 475-650 nm, several bands characteristic of ${ }^{5} \mathrm{D}_{4} \rightarrow{ }^{7} \mathrm{~F}_{\mathrm{J}(\mathrm{J}=3-6)}$ transitions of $\mathrm{Tb}^{3+}$ ions. ${ }^{5} \mathrm{D}_{4} \rightarrow{ }^{7} \mathrm{~F}_{5}$ transition is the most intense and confers to the materials a global greenish emission.

\section{Luminescence decays}

For practical applications, the lifetime of the emission is a very important parameter. Decay curves have been measured for the optima concentrations. Due to the very short radiative lifetime of $\mathrm{Ce}^{3+}$ ( $25 \mathrm{~ns}$ in $\mathrm{LuPO}_{4}$ ), the decay curve has not been measured for the $\mathrm{Ce}^{3+}$ doped samples.

The decay curves obtained for the co-precipitated $\mathrm{LuPO}_{4}: \mathrm{Eu}^{3+} 5 \%$ and for the sol-gel derived $\mathrm{LuPO}_{4}: \mathrm{Eu}^{3+} 5 \%$ and $\mathrm{LuPO}_{4}: \mathrm{Tb}^{3+} 5 \%$ samples have been measured. The decays were all fitted with a single exponential as shown in Figure 7. The lifetimes given on the graph are $3.9 \mathrm{~ms}, 2.5 \mathrm{~ms}$ and $2.5 \mathrm{~ms}$ for $\mathrm{LuPO}_{4}: \mathrm{Eu}^{3+} 5 \%$ co-precipitated, $\mathrm{LuPO}_{4}: \mathrm{Eu}^{3+} 5 \%$ and $\mathrm{LuPO}_{4}: \mathrm{Tb}^{3+} 5 \%$ sol-gel respectively. The shorter radiative lifetime of the sol-gel derived sample as compared to the coprecipitated one is related to higher residual $\mathrm{OH}$ concentration in the material prepared by sol-gel chemistry as observed for $\mathrm{YPO}_{4}$ [11]. The measured lifetimes are fully compatible with applications.

\section{Scintillation yields}

Scintillation yields have been measured for all the powders by comparing the integrating areas of the emission spectra of the sample and the reference (BGO or Gadox). Scintillation yields under $\gamma$-rays excitation are respectively 8060 photons/MeV [12] and 78000 photons/Mev [13] for BGO and Gadox. The yields of our materials were calculated from reference values which are obtained under $\gamma$-ray excitation. Our measurements have been performed under X-ray excitation, so the results given for the scintillation yields under $\gamma$-ray excitation might be under-estimated. The scintillation yields for all the samples and their evolution as a function of the doping ion concentration are presented in Figure 8. 
For $\mathrm{Ce}^{3+}$ doped $\mathrm{LuPO}_{4}$, the optimum is obtained for a Ce concentration of $0.1 \%$ with a scintillation yield of about 10200 photons/MeV. This result is in good agreement with the published value of 12000 photons/MeV [14]. The scintillation yield of $\mathrm{LuPO}_{4}: \mathrm{Ce}^{3+}$ has been improved by optimizing the $\mathrm{Ce}$ concentration. Indeed, recent work [15] presents the scintillation yield of different $\mathrm{Ce}$ doped materials and in particular the one of $\mathrm{LuPO}_{4}: \mathrm{Ce}^{3+}(1 \%)$ which was equal to 7400 photons/MeV. This paper [15] also presents results concerning the cerium oxidation state in cerium doped sol-gel derived materials indicating the presence of $\mathrm{Ce}^{4+}$ ions, so this observation can explain the fact that the measured yields are lower than those published in the literature. However, it is always difficult to compare the results obtained on single crystals and on powders. Moreover the results depend strongly on the experimental set-up.

In the case of $\mathrm{Eu}^{3+}$ doped $\mathrm{LuPO}_{4}$ powders, the maximum is obtained for $\mathrm{LuPO}_{4}: \mathrm{Eu}^{3+}(10 \%)$ when powders are elaborated by sol-gel process. For an europium concentration of 5\%, the scintillation yields are respectively about 5400 photons $/ \mathrm{MeV}$ and 9400 photons/ $\mathrm{MeV}$ for the material elaborated by sol-gel process and the one synthesized by co-precipitation. We can see that the scintillation yields obtained for the materials synthesized by co-precipitation are higher than those of the corresponding sol-gel derived materials. A possible explanation could be the presence of $\mathrm{OH}$ residual groups in the materials prepared by sol-gel route as already postulated from the lifetime measurements and illustrated by FTIR measurements.

Different scintillation yields have been measured for $\mathrm{LuPO}_{4}: \mathrm{Tb}^{3+}$, and particularly for $\mathrm{Tb}^{3+}$ concentration varying from 0.2 to $5 \%$. $\mathrm{LuPO}_{4}: \mathrm{Tb}^{3+}(5 \%)$ present the higher scintillation yield since this one is equal to about 9200 photons/MeV.

\section{Afterglow}

The afterglow value is an important characteristic for scintillating materials used in tomography. Indeed, for an application in tomography, the scintillator afterglow should be weak because a lot of images are recorded successively in a short time.

The afterglow behaviours for $\mathrm{Ce}^{3+}, \mathrm{Eu}^{3+}$ and $\mathrm{Tb}^{3+}$ doped $\mathrm{LuPO}_{4}$ powders are presented in Figure 9. The afterglow of Gadox $\left(\mathrm{Gd}_{2} \mathrm{O}_{2} \mathrm{~S}: \mathrm{Tb}\right)$ was also measured as a reference. The materials present an afterglow of $0.9 \%, 0.35 \%, 2.5 \%$ and $0.007 \%$ at $1 \mathrm{~s}$ after X-rays turn-off, for $\mathrm{LuPO}_{4}: \mathrm{Ce}^{3+}$ (0.1\%), $\mathrm{LuPO}_{4}: \mathrm{Tb}^{3+}(5 \%), \quad \mathrm{LuPO}_{4}: \mathrm{Eu}^{3+}(10 \%)$ elaborated by sol-gel process and Gadox respectively. The relatively high afterglow of $\mathrm{Eu}^{3+}$ doped samples could be restrictive for practical applications. $\mathrm{LuPO}_{4}: \mathrm{Eu}^{3+}(5 \%)$ synthesized by co-precipitation present an afterglow equal to $1 \%$ at $1 \mathrm{~s}$ after X-ray turn-off. 


\section{Conclusion}

The sol-gel process is a good technique which allows the elaboration of scintillating $\mathrm{LuPO}_{4}$ powders doped with different rare earth ions. These sol-gel derived powders present good cristallinity and purity, a homogeneous distribution of the particles and a controlled morphology. The scintillating properties of $\mathrm{Ce}^{3+}, \mathrm{Eu}^{3+}$ or $\mathrm{Tb}^{3+}$ doped $\mathrm{LuPO}_{4}$ powders were studied and high scintillation yields were obtained. These materials appear to be promising scintillators.

The optical properties of the prepared materials are not different from the ones of analogous solid state derived materials. The main advantage of sol-gel chemistry remains the possibility to prepare easily various compositions changing both the nature of the oxide matrix and the rare earth doping ions. The maximum possible concentration of doping ions is always higher for sol-gel derived materials than for the ones derived from solid state reaction and in particular single crystals. In some cases new compositions unreachable by solid state reaction are possible.

Furthermore, the sol-gel process developed in this work will allow the production of these materials as thin films which is a highly desirable configuration for X-ray intensifying screens.

Sol-gel process appears to be a simple and more flexible process for preparing oxides scintillators. In particular, it allows a high output screening of compositions and a high versatility in term of final shape.

\section{Acknowledgments}

Financial support from the French FRT under project LuminiX (RNTS-01B262) and from FNS under “ACI Nanostructures" project LuNaTIC (N5501) is acknowledged. 


\section{Figures captions}

Figure 1: X-Ray diffraction patterns recorded for (a) $\mathrm{LuPO}_{4}: \mathrm{Ce}^{3+}(1 \%)$, (b) $\mathrm{LuPO}_{4}: \mathrm{Eu}^{3+}(10 \%)$ and (c) $\mathrm{LuPO}_{4}: \mathrm{Tb}^{3+}(5 \%)$ with the corresponding reference patterns (dotted lines)

Figure 2: FTIR spectrum of $\mathrm{LuPO}_{4}$ powder heated at $1100^{\circ} \mathrm{C}$ for 24 hours

Figure 3: TG curve obtained from $\mathrm{LuPO}_{4}$ powder and first derivative curve (dotted line)

Figure 4: SEM micrographs of $\mathrm{LuPO}_{4}$ powders treated at $1100^{\circ} \mathrm{C}$ for 24 hours

Figure 5: Excitation spectra of $\mathrm{LuPO}_{4}: \mathrm{Ce}^{3+}, \mathrm{LuPO}_{4}: \mathrm{Eu}^{3+}$ and $\mathrm{LuPO}_{4}: \mathrm{Tb}^{3+}$ recorded at room temperature and respectively at $\lambda_{\mathrm{em}}=360 \mathrm{~nm}, \lambda_{\mathrm{em}}=592 \mathrm{~nm}$ and $\lambda_{\mathrm{em}}=541 \mathrm{~nm}$

Figure 6: Emission spectra recorded at room temperature under X-Ray excitation on (a) $\mathrm{LuPO}_{4}: \mathrm{Ce}^{3+}$, (b) $\mathrm{LuPO}_{4}: \mathrm{Eu}^{3+}$ and (c) $\mathrm{LuPO}_{4}: \mathrm{Tb}^{3+}$ (The emission spectra of $\mathrm{LuPO}_{4}: \mathrm{Eu}^{3+}$ powders synthesized by co-precipitation are not presented, but they are similar to the ones recorded for the $\mathrm{Eu}^{3+}$ doped powders elaborated by sol-gel process)

Figure 7: Decay curves recorded at room temperature for $\mathrm{LuPO}_{4}: \mathrm{Eu}^{3+} 5 \%$ co-precipitated (a), $\mathrm{LuPO}_{4}: \mathrm{Eu}^{3+} 5 \%$ sol-gel (b) and $\mathrm{LuPO}_{4}: \mathrm{Tb}^{3+} 5 \%$ sol-gel (c). Decays have been fitted with a single exponential and lifetimes are given on the graph.

Figure 8: Relative scintillation yields of $\mathrm{LuPO}_{4}: \mathrm{Ce}^{3+}, \mathrm{LuPO}_{4}: \mathrm{Eu}^{3+}$ and $\mathrm{LuPO}_{4}: \mathrm{Tb}^{3+}$ samples

Figure 9: Afterglow measurements on $\mathrm{LuPO}_{4}: \mathrm{Ce}^{3+}, \mathrm{LuPO}_{4}: \mathrm{Eu}^{3+}$ and $\mathrm{LuPO}_{4}: \mathrm{Tb}^{3+}$ and on Gadox under X-ray excitation with a $10 \mathrm{~s}$ irradiation time 


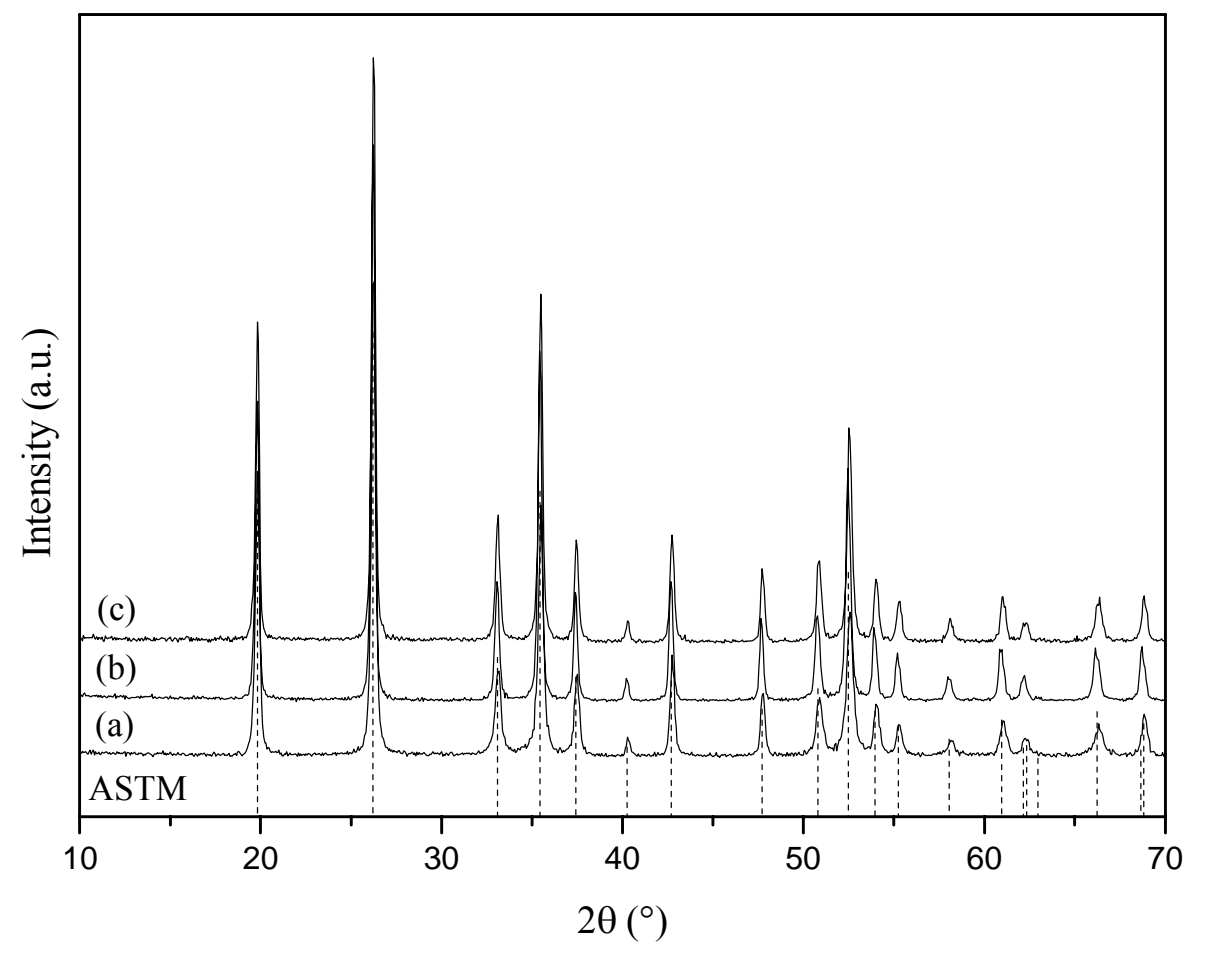

Figure 1: X-Ray diffraction patterns recorded for (a) $\mathrm{LuPO}_{4}: \mathrm{Ce}^{3+}(1 \%)$, (b) $\mathrm{LuPO}_{4}: \mathrm{Eu}^{3+}(10 \%)$ and (c) $\mathrm{LuPO}_{4}: \mathrm{Tb}^{3+}(5 \%)$ with the corresponding reference patterns (dotted lines) 


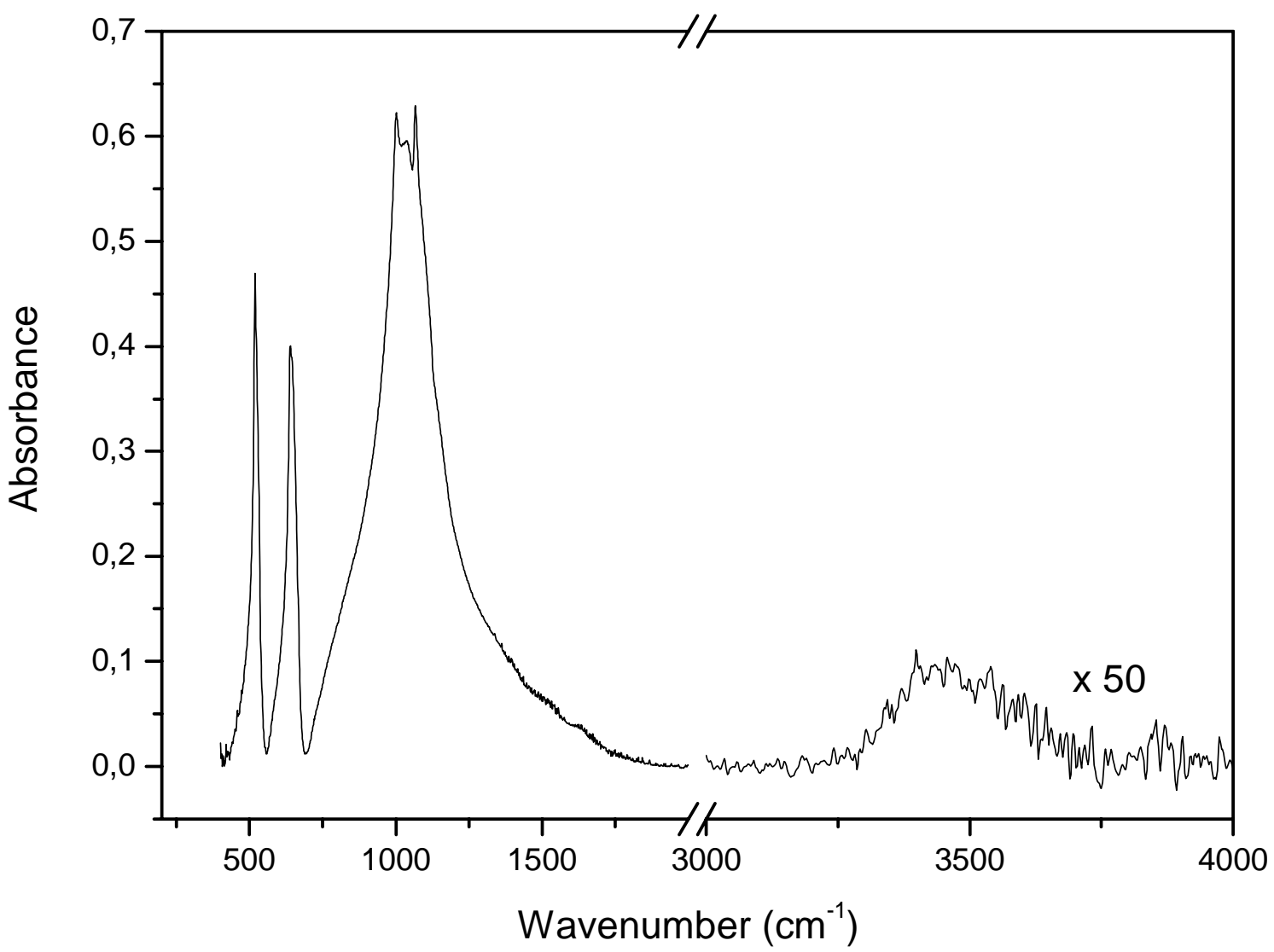

Figure 2: FTIR spectrum of $\mathrm{LuPO}_{4}$ powder heated at $1100^{\circ} \mathrm{C}$ for 24 hours 


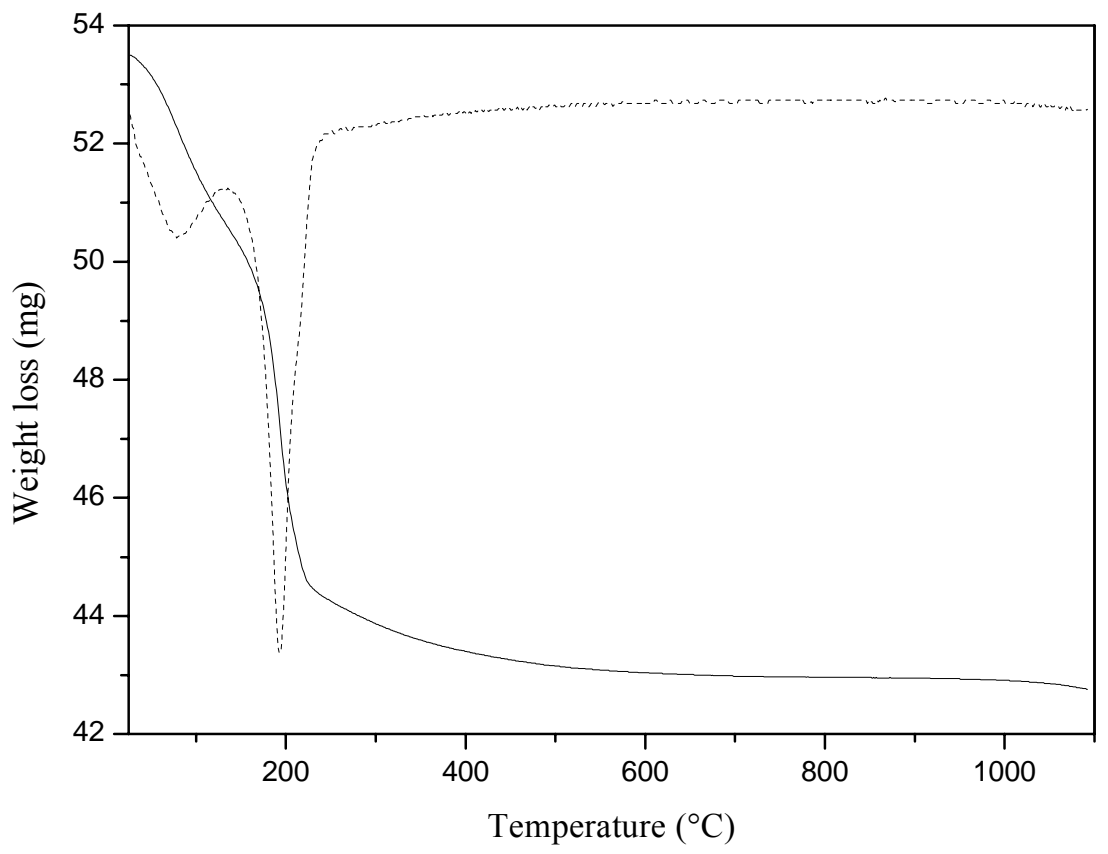

Figure 3: TG curve obtained from $\mathrm{LuPO}_{4}$ powder and first derivative curve (dotted line) 


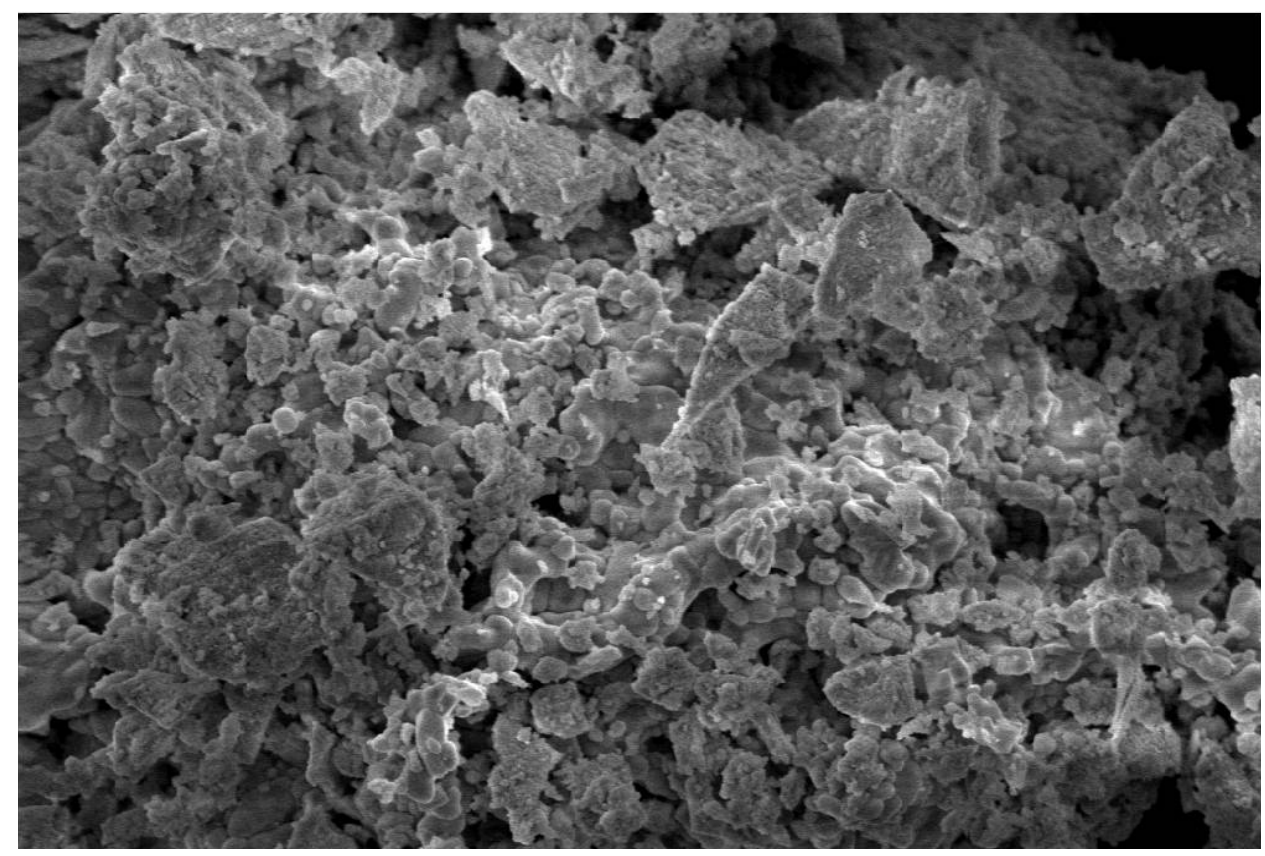

$10 \mu \mathrm{m}$

Figure 4: SEM micrographs of $\mathrm{LuPO}_{4}$ powders treated at $1100^{\circ} \mathrm{C}$ for 24 hours 

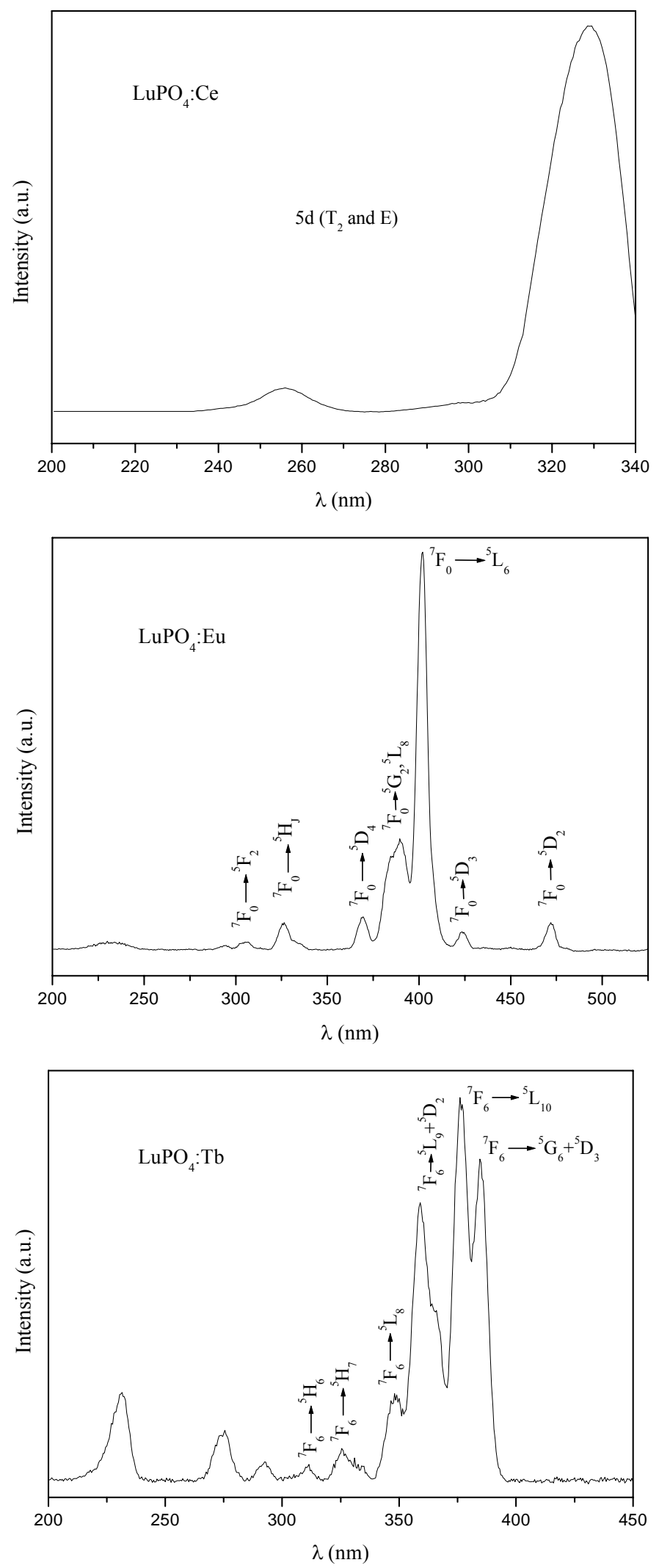

Figure 5: Excitation spectra of $\mathrm{LuPO}_{4}: \mathrm{Ce}^{3+}(0.5 \%), \mathrm{LuPO}_{4}: \mathrm{Eu}^{3+}(10 \%)$ and $\mathrm{LuPO}_{4}: \mathrm{Tb}^{3+}(5 \%)$ recorded at room temperature and respectively at $\lambda_{\mathrm{em}}=360 \mathrm{~nm}, \lambda_{\mathrm{em}}=592 \mathrm{~nm}$ and $\lambda_{\mathrm{em}}=541 \mathrm{~nm}$ 

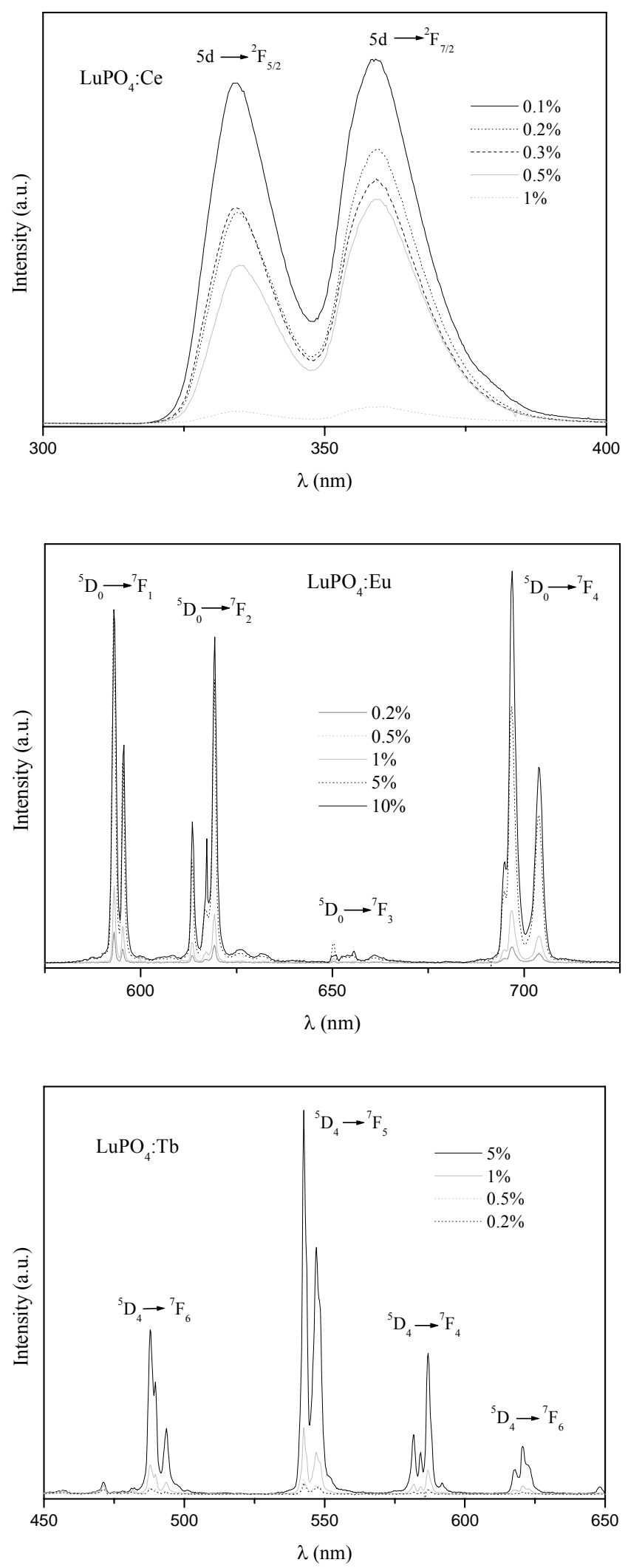

Figure 6: Emission spectra recorded at room temperature under X-Ray excitation on (a) $\mathrm{LuPO}_{4}: \mathrm{Ce}^{3+}$, (b) $\mathrm{LuPO}_{4}: \mathrm{Eu}^{3+}$ and (c) $\mathrm{LuPO}_{4}: \mathrm{Tb}^{3+}$ (The emission spectra of $\mathrm{LuPO}_{4}: \mathrm{Eu}^{3+}$ powders synthesized by coprecipitation are not presented, but they are similar to the ones recorded for the $\mathrm{Eu}^{3+}$ doped powders elaborated by sol-gel process) 

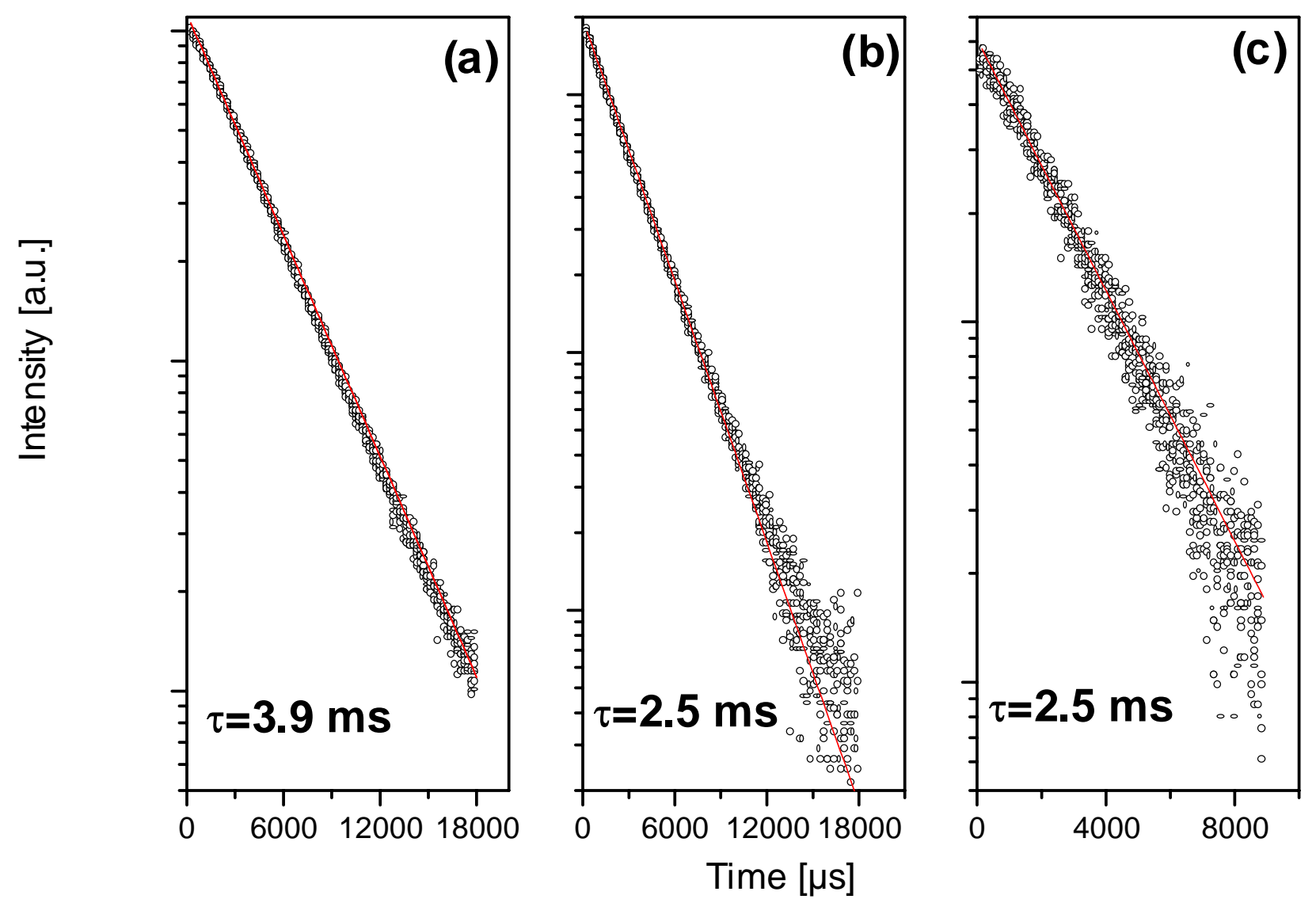

Figure 7: Decay curves recorded at room temperature for $\mathrm{LuPO}_{4}: \mathrm{Eu}^{3+} 5 \%$ co-precipitated (a), $\mathrm{LuPO}_{4}: \mathrm{Eu}^{3+} 5$ $\%$ sol-gel (b) and $\mathrm{LuPO}_{4}: \mathrm{Tb}^{3+} 5 \%$ sol-gel (c). Decays have been fitted with a single exponential and lifetimes are given on the graph. 


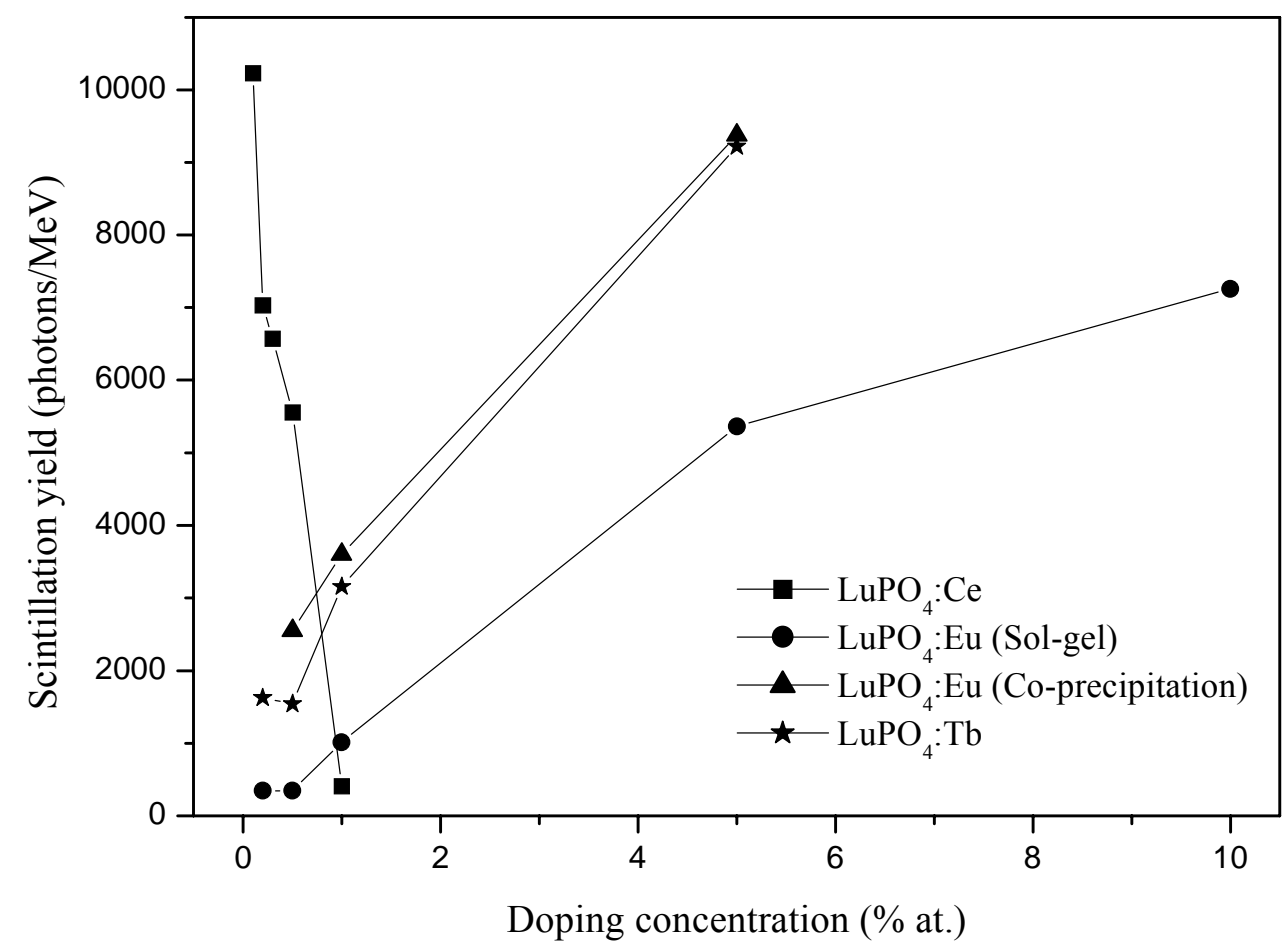

Figure 8: Relative scintillation yields of $\mathrm{LuPO}_{4}: \mathrm{Ce}^{3+}, \mathrm{LuPO}_{4}: \mathrm{Eu}^{3+}$ and $\mathrm{LuPO}_{4}: \mathrm{Tb}^{3+}$ samples 


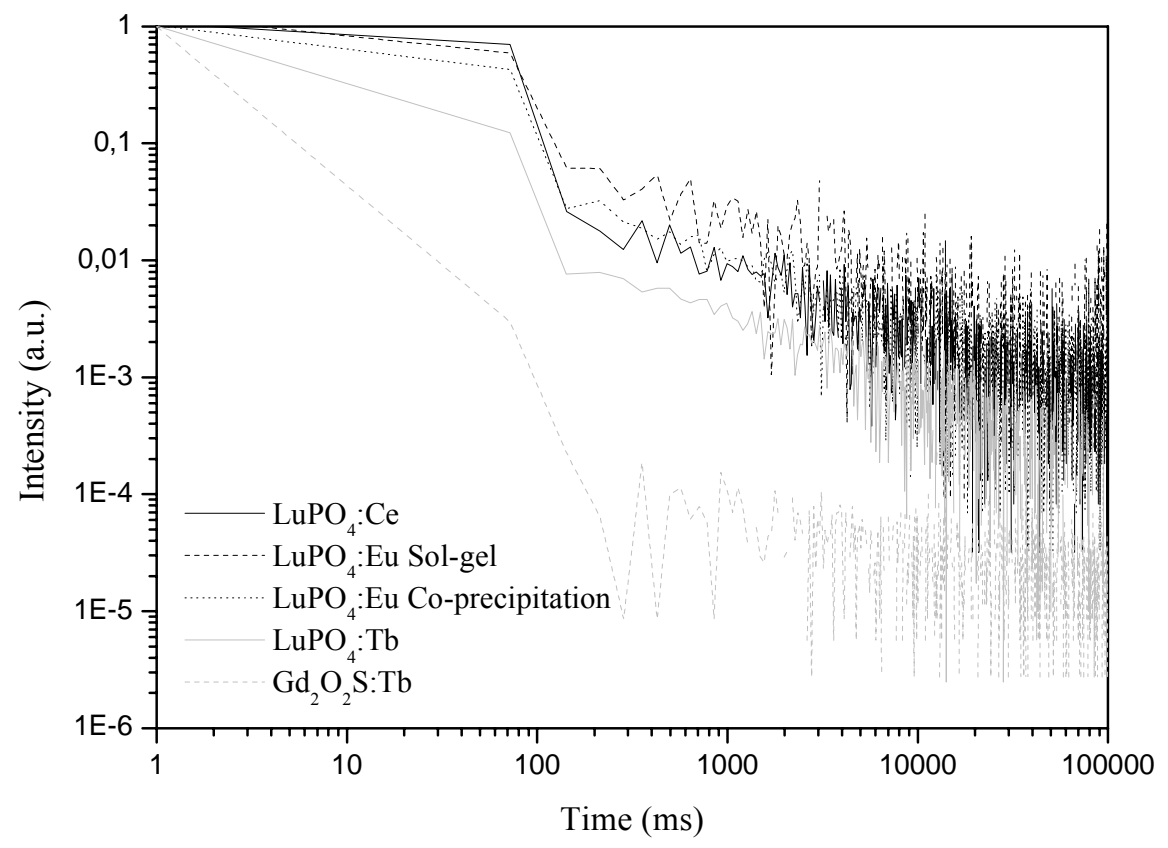

Figure 9: Afterglow measurements on $\mathrm{LuPO}_{4}: \mathrm{Ce}^{3+}, \mathrm{LuPO}_{4}: \mathrm{Eu}^{3+}$ and $\mathrm{LuPO}_{4}: \mathrm{Tb}^{3+}$ and on Gadox under X-ray excitation with a $10 \mathrm{~s}$ irradiation time 


\section{References}

[1] a) Proc. of Inorganic Scintillators and their Applications, Chamonix, France 2001; b) Proc. of Inorganic Scintillators and their Applications, Valencia, Spain 2003.

[2] a) A. Lempicki, E. Berman, A.J. Wojtowicz, M. Balcerayk, L.A. Boatner, IEEE Trans. Nucl. Sci., 1993, 40, 384; b) A.J. Wojtowicz, A. Lempicki, D. Wisniewski, M. Balcerzyk, C. Brecher, IEEE Trans. Nucl. Sci., 1996, 43, 2168; c) W.W. Moses, M.J. Weber, S.E. Derenzo, D. Perry, P. Berdahl, L.A. Boatner, IEEE Trans. Nucl. Sci., 1998, 45, 462; d) M. Balcerzyk, Z. Gontarz, M. Moszynski and M. Kapusta, J. Lum., 2000, 87-89, 963-966; e) D. Wisniewski, S. Tavernier, P. Dorenbos, M. Wisniewska, A.J. Wojtowicz, P. Bruyndonckx, E. van Loef, C.W.E. van Eijk, L.A. Boatner, IEEE Trans. Nucl. Sci., 2002, 49, 937.

[3] D. C. Bradley, R. C. Mehrotra and D. P. Gaur, Metal Alkoxides, Academic Press Inc., London, 1978.

[4] a) W.O. Milligan, D.F. Mullica, G.W. Beall and L.A. Boatner, Inorg. Chim. Acta, 1982, 60, 3943; b) W.O. Milligan, D.F. Mullica, G.W. Beall and L.A. Boatner, Acta Cryst., 1983, C39, 23-24; c) W.O. Milligan, D.F. Mullica, G.W. Beall and L.A. Boatner, Inorg. Chim. Acta, 1983, 70, 133-136. [5] a) G.W. Beall, L.A. Boatner, D.F. Mullica and W.O. Milligan, J. Inorg. Nucl. Chem., 1980, 43, 101-105 ; b) D.F. Mullica, W.O. Milligan et D.A. Grossie, Inorg. Chim. Acta, 1984, 95, 231-236 ; c) D.F. Mullica, D.A. Grossie and L.A. Boatner, J. Solid State Chem., 1985, 58, 71-77 ; d) D.F. Mullica, D.A. Grossie, Inorg. Chim. Acta, 1985, 109, 105-110; e) Yunxiang Ni, John M. Hughes, Anthony N. Mariano, American Mineralogist, 1995, 80, 21-26.

[6] a) S-L. Tie, Y-Y. Li and Y-S. Yang, J. Phys. Chem. Solids, 1997, 58 (6), 957-961; b) T. Masui, H. Hirai, N. Imanaka and G. Adachi, Phys. Stat. Sol. (a), 2003, 198 (2), 364-368.

[7] S.K. Ruan, J.G Zhou, A.M. Zhong, J.F. Duan, X.B. Yang and M.Z. Su, J. Alloys Compd., 1998, $275-277,72-75$

[8] L. Zhang, PhD Dissertation, 1998, Lyon I.

[9] D. Hreniak, E. Zych, L. Kepinski and W. Strek, J. Phys. Chem. Solids, 2003, 64, 111-119.

[10] M. Zawadzki, D. Hreniak, J. Wrzyszcz, W. Mista, H. Grabowska, O.L. Malta and W. Strek, Chem. Phys., 2003, 291 (3), 275-285.

[11] J.M. Nedelec, D. Avignant and R. Mahiou, Chem. Mat., 2002, 14, 651.

[12] M. Moszynski, M. Kapusta, M. Mayhugh, D. Wolski and S.O. Flyckt, IEEE Trans. Nucl. Sci., 1997, 44, 1052.

[13] L.H. Brixner, Mat. Chem. Phys., 1987, 16, 253. 
[14] M. Balcerzyk, Z. Gontarz, M. Moszynski and M. Kapusta, J. Lum., 2000, 87-89, 963-966.

[15] C. Mansuy, J-M Nedelec and R. Mahiou, J. Mater. Chem., 2004, 14, 3274-3280. 